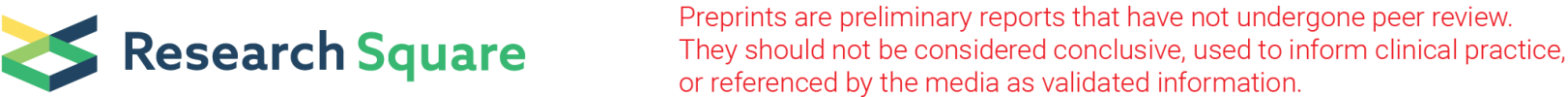

\section{The effects of naloxone, diazepam, and quercetin on seizure and sedation in acute on chronic tramadol administration: An experimental study}

\section{Samaneh Nakhaee}

Birjand University of Medical Sciences

Khadijeh Farrokhfall

Birjand University of Medical Sciences

Ebrahim Miri-Moghaddam

Birjand University of Medical Sciences

Mohsen Foadoddini

Birjand University of Medical Sciences

Masoumeh Askari

Birjand University of Medical Sciences

Alireza Amirabadizadeh

Birjand University of Medical Sciences

Jeffrey Brent

University of Colorado

\section{Bruno Megarbane}

University of Paris

omid Mehrpour ( $\nabla$ omid.mehrpour@yahoo.com.au )

Birjand University of Medical Sciences https://orcid.org/0000-0002-1070-8841

\section{Research}

Keywords: quercetin, diazepam, naloxone, neurotoxicity, tramadol

Posted Date: January 15th, 2021

DOI: https://doi.org/10.21203/rs.3.rs-137088/v1

License: (c) (i) This work is licensed under a Creative Commons Attribution 4.0 International License. Read Full License 


\section{Abstract}

Background: Tramadol is a widely used synthetic opioid. Substantial research has previously focused on the neurological effects of this drug, while the efficacy of various treatments to reduce the associated side effects has not been well studied. This study aimed to evaluate the protective effects of naloxone, diazepam, and quercetin on tramadol induced seizure and sedation level in male rats.

Methods: The project was performed with 72 male Wistar rats with an average weight of $200-250 \mathrm{~g}$. The rats were randomly assigned to 8 groups. Tramadol was administered intraperitoneally at an initial dose of $25 \mathrm{mg} / \mathrm{kg} /$ day. On the $14^{\text {th }}$ day, tramadol was injected at $75 \mathrm{mg} / \mathrm{kg}$, either alone or together with naloxone, diazepam, and quercetin (acute and chronic) in different combinations. The rats were monitored for 6 hours on the last day, and the number, the duration, and the severity of seizures (using the criteria of Racine) were measured at different times. The sedation level was also assessed based on a 4point criterion, ranging from 0 to 3 , at different times after injection. Data were analyzed in SPSS software using Kruskal-Wallis, Chi-square, multivariate regression, and generalized estimating equation (GEE) tests. The significance level was set at $\mathrm{P}<0.05$.

Results: The naloxone-diazepam combination reduced the number of seizures, severity, and duration of seizures compared to the tramadol use alone and reduced the number of higher-intensity seizures to a greater extent than other treatments. Naloxone alone reduced the number and duration of seizures, as well as the duration of mild seizures. Diazepam decreased the severity and duration of seizures. However, it increased the number of mild seizures. In comparison with the tramadol alone group, the acute quercetin group had a lower duration of mild and severe seizures, and higher numbers of mild and moderate seizures. Chronic quercetin administration decreased the duration of seizures and significantly increased the number of mild seizures. Naloxone-Quercetin also reduced the duration of mild and severe seizures significantly. In the GEE model, all groups had higher sedation levels than the saline only group $(P<0.001)$. None of the protocols had a significant effect on sedation levels compared to the other groups.

Conclusion: The combined administration of naloxone and diazepam in acute on chronic tramadol poisoning can effectively reduce most seizure variables, compared to the tramadol use alone. However, none of the treatments can improve sedation levels.

\section{Background}

Tramadol is widely used worldwide as a centrally acting analgesic to treat moderate to severe pain [1]. Given the increasing numbers of tramadol overdose and fatalities in recent decades, this drug has been classified as controlled substance in several countries [2]. Tramadol overdose can lead to loss of consciousness, seizures, respiratory depression, serotonin syndrome, and death [3, 4]. However, the molecular and biochemical mechanisms of tramadol toxicity are still poorly understood [5]. Recent 
studies have shown that tramadol increases oxidative stress in various body tissues including the brain, however the extent to which this occurs in acute toxicity, if any, is unknown [6]. Nevertheless, tramadol overdose has been shown to cause brain congestion, edema, and inflammatory infiltrates in the rat [7]. Chronic tramadol administration at a dose of $50 \mathrm{mg} / \mathrm{kg}$ causes histological abnormalities demonstrating oxidative stress-related apoptosis in the rat cortex $[8,9]$. Similarly, chronic low but escalating tramadol doses has also been associated with neuronal degeneration in rat model[10]

Tramadol causes self-limiting tonic-clonic seizures within 4 to 6 hours after administration, although electroencephalographic (EEG) changes, recurrent seizures, or persistent epilepsy are not uncommon as evidenced in the rodent models [4]. In humans, tramadol-induced seizures appear to be dose-independent and may occur even within the recommended treatment range, although they are clearly more common when patients exceed recommended doses [11]. The cause of tramadol-induced seizures is not well understood. Nevertheless, based on findings from animal studies, it is unlikely that seizures are related to the serotonergic effects of tramadol [12]. Alternative pathways involving opioid, histamine, or GABA receptors, have been implicated in tramadol seizurgenesis [4]. It is well established that inhibition of GABAergic neurons or activation of glutamatergic neurons leads to seizures. Tramadol, and its metabolite $\mathrm{M} 1$, inhibit gamma-aminobutyric acid (GABA)-A receptors at high concentrations and glutaminergic $\mathrm{N}$ methyl-D-aspartate (NMDA) receptors at clinically relevant concentrations [13].

Naloxone is an opioid receptor antagonist that reverses opioid-induced respiratory depression. However, there are conflicting findings on its use in tramadol poisoning and its effect on seizures [11]. Previous experimental and human investigations have shown that naloxone may reduce $[11,14]$, increase $[4,15$, 16], or have no impact [17] on the risk of tramadol-induced seizures. Benzodiazepines act as a GABA-A/B receptor enhancer and, thus, may tend to protect against and reverse seizures due to tramadol $[3,13]$. Experimental studies have demonstrated that benzodiazepines are effective in the prophylaxis of $t$ tramadol overdose-induced seizures [3], and more limited seizure activity has been reported in patients co-ingesting tramadol and benzodiazepines [16]. In contrast, fatalities have been reported with the coingestion of benzodiazepines and tramadol [18], although the exact mechanisms of such drug-drug interactions are not fully known.

Found in vegetables and fruits, quercetin is a flavonoid with many attributed therapeutic and protective properties, including antioxidant and anti-inflammatory activities $[19,20]$. Neuroprotective effects of quercetin on various central nervous system disorders such as memory impairment [21,22] and seizures $[19,20,23]$ have been reported. An animal study investigating the effect of quercetin on GABA-a5 receptor gene expression in kainic acid-induced seizures indicated increased expression of GABA-a5 receptor gene in the hippocampus of the kainic acid group, whereas expression decreased in the quercetin group [19].

To our knowledge, no study investigating the acute-on-chronic neurological effects of tramadol is available. This is important because who are using tramadol chronically may intentionally or accidently overdose. Moreover, the potential protective effects of quercetin, diazepam, and naloxone on the nervous system in acute-on-chronic use of tramadol are unknown. This study aimed to investigate the protective 
effects, if any, of quercetin, diazepam, and naloxone on tramadol-induced toxicity in an acute on chronic model in male rats.

\section{Methods}

This study was performed with 72 male Wistar rats (body weight, 200-250 g, age, 12 weeks). All experiments were performed as per the international rules for laboratory animals and in conditions agreed by the Research Centre of Experimental Medicine, Birjand University of Medical Sciences (BUMS). Rats were kept in constant room temperature $\left[22 \pm 2^{\circ} \mathrm{C}\right.$, light/dark $12 \mathrm{~h}$ intervals] and free access to food and water in the BUMS animal facility. The BUMS ethics committee approved the study protocol (identifier: IR.BUMS.REC.1397.194). Healthy Wistar rats with normal behavior and activity were included. Previously used rats from other experimental studies were not included. Exclusion criteria were considered as death during experiment.

Quercetin, naloxone, diazepam, and pentobarbital were purchased from the Sigma-Aldrich Company, and tramadol was obtained from the Temad Company (Iran, Karaj). Quercetin, diazepam, and naloxone were dissolved in DMSO, and tramadol in normal saline. The concentration of DMSO in this study was $2 \%$. The injection volume was $1 \mathrm{ml} / \mathrm{kg}$. The DMSO was administrated in normal the inert range for behavioral[24] and animal experimental studies pharmacological studies [25]. The animals were randomly assigned to 8 groups of 9 animals, each after one week of adaptation to laboratory conditions. The calculation of sample size is based on the "resource equation approach" design for animal studies using the formula of $\mathrm{N}=(10 / k+1) \times k$, where $N=$ total number of subjects, $k=$ number of groups [26]. The first group (Contro) received $0.9 \%$ saline intraperitoneally for 14 days. The second group (Tramadol) received $25 \mathrm{mg} / \mathrm{kg}$ tramadol IP for 13 days and $75 \mathrm{mg} / \mathrm{kg}$ tramadol IP on the $14^{\text {th }}$ day. Group 3 (Naloxone) received 25 $\mathrm{mg} / \mathrm{kg}$ tramadol IP for 13 days and $75 \mathrm{mg} / \mathrm{kg}$ tramadol IP on the $14^{\text {th }}$ day, along with a $2 \mathrm{mg} / \mathrm{kg}$ naloxone intravenously (IV) bolus $15 \mathrm{~min}$ after tramadol injection, followed by $4 \mathrm{mg} / \mathrm{kg} / \mathrm{h}$ naloxone injection for up to 6 hours [4]. Group 4 (Diazepam) received $25 \mathrm{mg} / \mathrm{kg}$ tramadol IP for 13 days and 75 $\mathrm{mg} / \mathrm{kg}$ tramadol IP on the $14^{\text {th }}$ day along with $1.77 \mathrm{mg} / \mathrm{kg}$ of diazepam IP $15 \mathrm{~min}$ after tramadol injection. Group 5 (Naloxone-Diazepam) received $25 \mathrm{mg} / \mathrm{kg}$ tramadol IP for 13 days and $75 \mathrm{mg} / \mathrm{kg}$ tramadol IP on the $14^{\text {th }}$ day, together with $1.77 \mathrm{mg} / \mathrm{kg}$ diazepam IP and $2 \mathrm{mg} / \mathrm{kg}$ naloxone IV followed by $4 \mathrm{mg} / \mathrm{kg} / \mathrm{h}$ naloxone injection for up to 6 hours. Group 6 (Acute Quercetin) received $25 \mathrm{mg} / \mathrm{kg}$ tramadol IP for 13 days and $75 \mathrm{mg} / \mathrm{kg}$ tramadol IP on the $14^{\text {th }}$ day, followed by $100 \mathrm{mg} / \mathrm{kg}$ quercetin IP. Group 7 (Chronic Quercetin) received $25 \mathrm{mg} / \mathrm{kg} /$ day tramadol IP and $100 \mathrm{mg} / \mathrm{kg} /$ day quercetin IP followed by 75 $\mathrm{mg} / \mathrm{kg}$ tramadol IP on the $14^{\text {th }}$ day. Group 8 (Quercetin-Naloxone) received $25 \mathrm{mg} / \mathrm{kg} /$ day tramadol IP for 13 days and $75 \mathrm{mg} / \mathrm{kg}$ tramadol IP on the $14^{\text {th }}$ day followed by $100 \mathrm{mg} / \mathrm{kg}$ quercetin IP and $2 \mathrm{mg} / \mathrm{kg}$ naloxone IV followed by $4 \mathrm{mg} / \mathrm{kg} / \mathrm{h}$ naloxone injection for up to 6 hours (Figure 1).

The rats were clinically monitored during 6 hours on the last day regarding the number, duration, and severity of seizures and sedation level. The sedation level was assessed based on a 4-point scale, ranging from 0 to 3 . In stage 0 (awake), rats were fully awake, and their gait and reflexes were entirely 
intact. In stage 1 (lethargic), rat activities were reduced, and they experienced mild gait abnormalities and reduced muscle tone, while the straightening reflexes were normal. In stage 2 (mild comatose), rats were dormant and immobile, and the straightening reflexes decreased. In stage 3 (deep coma), rats were comatose and had no straightening reflexes [4]. The straightening reflex was measured by placing the animal on its back to see its ability to stand or return to normal [27].

Seizure severity was rated according to the criteria of Racine. In stage 1, rats were immobile, with closed eyes and facial clonus, while the hair around the nose was shaking. In stage 2 , rats experienced headshaking accompanied by more severe facial clonus. In stage 3 , rats exhibited forelimb clonus. In stage 4, rats rose on their hind legs and exhibited bilateral forelimb clonus. In stage 5, rats rose on their hind legs, had no balance, fell, and underwent generalized clonic seizures [4]. All behavioral tests were recorded by a video camera connected to a video recorder. Videos were subsequently analyzed by a trained observer. At the end of the behavioral recording, rats were released and cared for at the BUMS animal house.

The experimenter was aware of the rat group, but a researcher blinded to the group allocation carried out statistical analysis and outcome assessment. Collected data were analyzed using SPSS software 16. The normality of quantitative variables was checked using Shapiro-Wilk tests. Kruskal-Wallis, Dunn-Bonferroni post hoc, and multivariate regression tests were used to compare quantitative parameters and chi-square tests to compare qualitative parameters. The generalized estimating equation (GEE) model was employed to analyze the longitudinal variables measured at different time points. In the GEE model, longitudinal variables were entered into the model as dependent variables and groups as explanatory variables. As a dependent variable, the sedation level was measured and recorded immediately, at $15 \mathrm{~min}$, $30 \mathrm{~min}, 1 \mathrm{~h}, 2 \mathrm{~h}, 3 \mathrm{~h}, 4 \mathrm{~h}, 5 \mathrm{~h}$, and $6 \mathrm{~h}$ after tramadol injection. P-value less than 0.05 was considered significant.

\section{Results}

One death occurred in each of the chronic Quercetin, Quercetin-Naloxone, and Tramadol-Naloxone groups during the study. At baseline, rat weight did not differ between groups $(p>0.05)$. However, at the end of the study, weight of the Chronic Quercetin group was significantly lower than that of the Tramadol and Control groups $(p<0.05)$. The number of seizures in all experimental groups was significantly higher than that of the Control group. However, the rats in the Naloxone-Diazepam group had significantly decreased number of seizures, compared to rats in the Tramadol group (Figure 2). The Naloxone, Diazepam, Naloxone-Diazepam, and Acute Quercetin groups showed significantly reduced seizure severity, compared to the Tramadol group. Moreover, all groups experienced significantly reduced seizure duration, compared to the Tramadol group $(p<0.05)$ (Figure 2).

The number of moderate (level 3) and severe (level 4) seizures in the Naloxone-Diazepam group was significantly lower than that of other groups $(\mathrm{P}<)$. Diazepam was associated with a significantly higher ratio of mild seizures and a lower proportion of severe seizures $(P<)$. The Acute Quercetin group showed a significantly higher number of low-intensity (level 2) and moderate (level 3) seizures than the Tramadol 
group $(\mathrm{P}<)$. Chronic Quercetin and Naloxone, compared to Tramadol, only significantly increased the number of low-intensity (level 2) seizures $(\mathrm{P}<$ ) (Figure 3). The Naloxone, Acute Quercetin, and QuercetinNaloxone groups significantly reduced the duration of seizures with severity degrees of 2,3 , and 4 , as compared to the Tramadol group $(\mathrm{P}<)$. Moreover, the Diazepam and Chronic Quercetin groups significantly reduced the seizures with severity degrees of 2 and 3 , compared to the Tramadol group $(P<)$ (Figure 3).

The results of multivariate regression analysis showed that seizure severity in the Naloxone $(P=0.03, \beta=$ -0.40), Diazepam $(P<0.001, \beta=-0.85)$, and Naloxone-Diazepam $(P<0.001, \beta=11.55)$ groups decreased significantly, in comparison with the Tramadol group. Also, the duration of seizures in the Naloxone ( $P$ $<0.001, \beta=-4.22)$, Diazepam $(P<0.001, \beta=-3.78)$, and Acute Quercetin $(P<0.001, \beta=-5.20)$ groups decreased significantly compared to the Tramadol group (Table 1).

Table 1: Results of multivariate regression analysis (seizure severity and seizure duration) in the different groups

\begin{tabular}{llcccc}
\hline Variable & & $\mathrm{B}$ & $\mathrm{SE}$ & $\mathrm{t}$ & $\mathrm{p}$-value \\
\hline Severity of seizures & Naloxone vs Tramadol & -0.40 & 0.18 & 2.19 & 0.03 \\
\cline { 2 - 6 } & Diazepam vs Tramadol & -0.85 & 0.18 & 2.19 & $<0.001$ \\
\cline { 2 - 6 } & Naloxone-Diazepam vs Tramadol & -1.55 & 0.33 & -4.65 & $<0.001$ \\
\cline { 2 - 6 } & Acute Quercetin vs Tramadol & -0.21 & 0.16 & 1.29 & 0.20 \\
\cline { 2 - 6 } & Chronic Quercetin vs Tramadol & 0.04 & 0.18 & 0.23 & 0.81 \\
\cline { 2 - 6 } & Quercetin-Naloxone vs Tramadol & 0.01 & 0.21 & 0.07 & 0.94 \\
\hline Duration of seizures & Naloxone vs Tramadol & -4.22 & 1.13 & -3.73 & $<0.001$ \\
\cline { 2 - 6 } & Diazepam vs Tramadol & -3.78 & 1.14 & -3.32 & $<0.001$ \\
\cline { 2 - 6 } & Naloxone-Diazepam vs Tramadol & -3.15 & 2.05 & -1.54 & 0.12 \\
\cline { 2 - 6 } & Acute Quercetin vs Tramadol & -5.20 & 1.02 & -5.11 & $<0.001$ \\
\cline { 2 - 6 } & Chronic Quercetin vs Tramadol & -1.69 & 1.11 & -1.52 & 0.13 \\
\cline { 2 - 6 } & Quercetin-Naloxone vs Tramadol & -0.61 & 1.29 & -0.48 & 0.63 \\
\hline
\end{tabular}

In the GEE model, the sedation leve/ was considered as dependent variable and the group as explanatory variable. All groups had a higher sedation level than the Control group. In the GEE model analysis, the Tramadol group showed a 0.59 higher sedation level than the Control group $(P<0.05)$. The QuercetinNaloxone group showed 0.70 more sedation than the control group $(P<0.001)$; this group had the highest increase in sedation level. None of the treatments had a positive effect on the sedation level (Table 2). 
The highest sedation level occurred 30 to 60 min after tramadol administration and the sedation level approached zero about $3 \mathrm{~h}$ after tramadol administration (Figure 4).

Table 2: Comparison of sedation levels in the different groups vs the Control and Tramadol groups based on the GEE model

\begin{tabular}{lcccc}
\hline Variable & B & SE & Wald & p-value \\
\hline Tramadol vs Control & 0.59 & 0.04 & 192.53 & $<0.001$ \\
\hline Naloxone vs Control & 0.56 & 0.04 & 162.00 & $<0.001$ \\
\hline Diazepam vs Control & 0.59 & 0.04 & 192.53 & $<0.001$ \\
\hline Naloxone-Diazepam vs Control & 0.64 & 0.06 & 100.04 & $<0.001$ \\
\hline Acute Quercetin vs Control & 0.67 & 0.07 & 93.03 & $<0.001$ \\
\hline Chronic Quercetin vs Control & 0.64 & 0.04 & 194.32 & $<0.001$ \\
\hline Quercetin-Naloxone vs Control & 0.70 & 0.07 & 113.28 & $<0.001$ \\
\hline Naloxone vs Tramadol & -0.03 & 0.06 & 0.25 & 0.61 \\
\hline Diazepam vs Tramadol & $-5.06 \mathrm{e}-18$ & 0.06 & 0.0001 & 1.00 \\
\hline Naloxone-Diazepam vs Tramadol & 0.04 & 0.08 & 0.32 & 0.57 \\
\hline Acute Quercetin vs Tramadol & 0.08 & 0.08 & 0.91 & 0.34 \\
\hline Chronic Quercetin vs Tramadol & 0.04 & 0.06 & 0.52 & 0.47 \\
\hline Quercetin-Naloxone vs Tramadol & 0.11 & 0.07 & 1.93 & 0.16 \\
\hline
\end{tabular}

\section{Discussion}

Our study demonstrates that the naloxone-diazepam combination reduces the number, severity, and duration of tramadol-induced seizures in acute-on-chronically tramadol-treated rats. This combination decreased the number of severe seizures, compared to other groups. However, it did not improve sedation.

Naloxone, the antidote used to reverse opioid overdose in humans, is a competitive opioid receptor antagonist. It has been shown to potentiate the anticonvulsant effects of benzodiazepines and barbiturates, thus exerting mild anticonvulsant effects [28]. Lagard et al. (2017) evaluated the effectiveness in the rat of naloxone and diazepam on tramadol-induced seizures and respiratory depression using EEG and plethysmography, respectively after an acute single-administration of 75 $\mathrm{mg} / \mathrm{kg}$ of tramadol. They showed that the diazepam-naloxone combination is the most effective treatment for relieving tramadol-induced seizures and improving ventilation. In the present study with acute-on-chronic tramadol exposure, naloxone reduced the number and duration of seizures.

Nevertheless, contradictory results have been reported regarding naloxone-attributed effects on tramadol poisoning and seizures. Similar to the present study, some studies have shown the protective effects of naloxone against opioid- and non-opioid-induced seizures. Consistent, naloxone administration reduced tramadol-induced seizure activity in mice treated with pentylenetetrazole [29]. The authors proposed an opioid-dependent GABAergic inhibitory pathway to explain tramadol-induced seizures. Similarly, another study showed that naloxone significantly reduced seizures induced by meperidine and its seizurogenic metabolite normeperidine, in mice [30]. Moreover, 12 hours of continuous naloxone injection in a rat model of kainic acid-induced seizures resulted in dose-dependent protective effects [31]. 
In humans, seizures have been attributed to naloxone as an adverse effect in opioid-poisoned patients [15]. This onset has been attributed to the potential disruptive effects of other associated toxins and to withdrawal in opioid-dependent individuals; it has also been seen as consequence of long-term hypoxia $[4,32]$. Lagard et al. (2017) showed that naloxone increased the number of seizures and prolonged their onset, but reduced respiratory depression [4]. In another study in mice, tramadol-induced seizures occurred mainly with high doses of naloxone [33]. Experimental data on seizures resulting from naloxone administration may vary depending on the animal model and experimental conditions. According to a meta-analysis of human studies, naloxone administration was not associated with seizures [34].

In the present study, diazepam reduced the severity and duration of seizures in acute-on-chronically exposed rats. It increased the number of mild seizures, yet significantly reduced the frequency of severe seizures. In line with the present study results, Lagard et al. (2017) also showed that diazepam relieved tramadol-induced seizures but significantly deepened the sedation level in rats [4]. The same group examined the effects of $20 \mathrm{mg} / \mathrm{kg}$ subcutaneous diazepam administration on tramadol neurotoxicity in rats showing that diazepam did not increase tramadol-induced mortality but significantly altered the pattern of toxicity by preventing seizures and enhancing respiratory depression [3]. Some studies have reported that patients who abuse tramadol along with benzodiazepines have a lower rate of seizures, though not statistically significant, than individuals who abuse tramadol along with heroin [35]. Some reports did not consider anticonvulsant prophylaxis to be necessary for patients overdosed with tramadol because the treatment of tramadol-induced seizures with benzodiazepines may have additive or synergistic effects on the GABA receptor, leading to exacerbated loss of consciousness in patients [16]. There have also been several reports concerning the point that benzodiazepines, even at therapeutic doses, may increase the morbidity and mortality of tramadol overdose [18, 36], possibly due to the cumulative CNS depressive effects.

Acute quercetin use reduced the duration but increased the number of mild to severe tramadol-induced seizures. Chronic quercetin administration reduced the duration of tramadol-induced seizures, had no effect on their severity, and significantly increased the number of mild episodes. The quercetin-naloxone group also showed a reduced duration of severe and mild seizures but had no effect on the number of seizures. As far as we know, quercetin effectiveness in tramadol-induced seizures has not been studied until now. However, its protective effects against other drug-induced seizures have been reported. For example, quercetin reduced kainic acid-induced seizure score in a dose-dependent manner [19]. The anticonvulsant potential of quercetin has been demonstrated at doses of 10 to $200 \mathrm{mg} / \mathrm{kg}$ in $6 \mathrm{~Hz}-$ induced convulsive seizures, the highest quercetin-related anticonvulsant activity being associated with high plasma and cerebral concentrations [23]. The exact anticonvulsant effects of quercetin and other flavonoids is not known, possibly mediated by their antioxidant properties [37, 38], interaction with GABA receptors, glycine [39], acetylcholine [23], serotonin receptors, [40] and adenosine [41].

Our empirical study has limitations including the fact that the generalization of animal findings to humans must be done with caution. These findings can only be considered as representative of the complex clinical condition in humans. However, our model exhibited tramadol-induced decreased level of 
consciousness and seizures similar to that reported in humans [42-44]. We realize that therapeutic studies in animals are only hypothesis for what may happen in human clinical use. Assessing the validity of any of hypotheses generated requires human data. In this study, we utilized single-dose treatments. Further research may be of utility by generating dose-response data. Further experimental and clinical research is needed to demonstrate the molecular mechanism of the effect of these treatments on tramadol overdose.

\section{Conclusion}

Combination of naloxone and diazepam in acute-on-chronic tramadol poisoning can effectively reduce the number, severity, and duration of seizures in the rat. This combination also decreases the number of severe seizures, compared to other treatments including naloxone alone, diazepam alone and quercetin. However, none of the tested treatments improves sedation. Understanding the exact clinical effects of the various drugs with potential interest used in this research project will pave the way for future research studies and their application to control tramadol-related toxicity in patients. This is important because patients who are using tramadol chronically may intentionally or accidently overdose. Our data was in an acute on chronic model and may be less applicable to patients who overdose on tramadol without prior use. .

\section{Abbreviations}

GEE: generalized estimating equation, EEG: electroencephalography, GABAA: $ү$-Aminobutyric acid type A, NMDA: N-methyl-D-aspartate, DMSO: Dimethyl sulfoxide, IP: intraperitoneal, CNS: central nervous system.

\section{Declarations}

\section{Ethics approval and consent to participate}

All experiments and treatments of rats were conducted according to the international laws of handling laboratory animals. The study protocol was also confirmed by the ethics committee of Birjand University of medical sciences (code: IR.BUMS.REC.1397.194).

\section{Consent for publication}

Not applicable

\section{Competing Interest}

The authors take full responsibility for the writing and content of this article, and confirm that there are no conflicts of interests associated with this academic publication

\section{Funding}


This study was supported by grants from the research council of Birjand University of Medical Sciences (Grant number: 455668), Birjand, Iran, and from the Iran National Science Foundation (INSF) (Grant number: 97012231). The funding body had no role in the design of the study and collection, analysis, and interpretation of data and in writing the manuscript.

\section{Authors' contributions}

$\mathrm{SN}, \mathrm{KF}, \mathrm{EM}, \mathrm{MF}, \mathrm{OM}$ contributed to conception, design, and preparation of the manuscript. SN, KF, MA, AA, OM contributed to conducting experiments, acquisition, analysis, and interpretation. SN, KF, EM, MF, MA, $\mathrm{AA}, \mathrm{BM}, \mathrm{JB}$ and $\mathrm{OM}$ made substantial contributions in drafting the manuscript and revising it critically for important intellectual content. All authors have read and approved the final version of manuscript.

\section{Acknowledgements}

Not applicable

\section{Availability of data and materials}

The datasets are available from the corresponding author on formal and logic request.

\section{References}

[1] Kaye AD. Tramadol, pharmacology, side effects, and serotonin syndrome: a review. ASIPP 2015;18: 395-400.

[2] Randall C, Crane J. Tramadol deaths in Northern Ireland: a review of cases from 1996 to 2012. Journal of forensic and legal medicine 2014;23: 32-36.

[3] Lagard C, Chevillard L, Malissin I, Risède P, Callebert J, Labat L, Launay J-M, Laplanche J-L, Mégarbane B. Mechanisms of tramadol-related neurotoxicity in the rat: Does diazepam/tramadol combination play a worsening role in overdose? Toxicology and Applied Pharmacology 2016;310: 108119.

[4] Lagard C, Malissin I, Indja W, Risède P, Chevillard L, Mégarbane B. Is naloxone the best antidote to reverse tramadol-induced neuro-respiratory toxicity in overdose? An experimental investigation in the rat. Clinical Toxicology 2017: 1-7.

[5] Barbosa J, Faria J, Leal S, Afonso LP, Lobo J, Queirós O, Moreira R, Carvalho F, Dinis-Oliveira RJ. Acute administration of tramadol and tapentadol at effective analgesic and maximum tolerated doses causes hepato-and nephrotoxic effects in Wistar rats. Toxicology 2017;389: 118-129.

[6] Abdel-Zaher AO, Abdel-Rahman MS, ELwasei FM. Protective effect of Nigella sativa oil against tramadol-induced tolerance and dependence in mice: role of nitric oxide and oxidative stress. Neurotoxicology 2011;32: 725-733. 
[7] Samaka R, Girgis N, Shams T. Acute toxicity and dependence of tramadol in albino rats: relationship of nestin and notch 1 as stem cell markers. J. of American Science 2012;8: 313-327.

[8] Ghoneim FM, Khalaf HA, Elsamanoudy AZ, Helaly AN. Effect of chronic usage of tramadol on motor cerebral cortex and testicular tissues of adult male albino rats and the effect of its withdrawal: histological, immunohistochemical and biochemical study. International journal of clinical and experimental pathology 2014;7: 7323.

[9] Baghishani F, Mohammadipour A, Hosseinzadeh H, Hosseini M, Ebrahimzadeh-bideskan A. The effects of tramadol administration on hippocampal cell apoptosis, learning and memory in adult rats and neuroprotective effects of crocin. Metabolic brain disease 2018: 1-10.

[10] Atici S, Cinel L, Cinel I, Doruk N, Aktekin M, Akca A, Camdeviren H, Oral U. Opioid neurotoxicity: comparison of morphine and tramadol in an experimental rat model. International journal of neuroscience 2004;114: 1001-1011.

[11] Eizadi-Mood N, Ozcan D, Sabzghabaee AM, Mirmoghtadaee P, Hedaiaty M. Does naloxone prevent seizure in tramadol intoxicated patients? International journal of preventive medicine 2014;5: 302.

[12] Fujimoto Y, Funao T, Suehiro K, Takahashi R, Mori T, Nishikawa K. Brain serotonin content regulates the manifestation of tramadol-induced seizures in ratsdisparity between tramadol-induced seizure and serotonin syndrome. Anesthesiology: The Journal of the American Society of Anesthesiologists 2015;122: 178-189.

[13] Hara K, Minami K, Sata T. The effects of tramadol and its metabolite on glycine, $Y$-aminobutyric AcidA, and N-methyl-d-aspartate receptors expressed in Xenopus oocytes. Anesthesia \& Analgesia 2005;100: 1400-1405.

[14] Saidi H, Ghadiri M, Abbasi S, Ahmadi S-F. Efficacy and safety of naloxone in the management of postseizure complaints of tramadol intoxicated patients: a self-controlled study. Emergency Medicine Journal 2010: emj. 2009.083162.

[15] Farzaneh E, Mostafazadeh B, Mehrpour O. Seizurogenic effects of low-dose naloxone in tramadol overdose. Iranian Journal of Pharmacology and Therapeutics 2012;11: 6-0.

[16] Shadnia S, Brent J, Mousavi-Fatemi K, Hafezi P, Soltaninejad K. Recurrent seizures in tramadol intoxication: implications for therapy based on 100 patients. Basic \& clinical pharmacology \& toxicology 2012;111: 133-136.

[17] Tashakori A, Afshari R. Tramadol overdose as a cause of serotonin syndrome: a case series. Clinical Toxicology 2010;48: 337-341.

[18] Clarot F, Goulle J, Vaz E, Proust B. Fatal overdoses of tramadol: is benzodiazepine a risk factor of lethality? Forensic science international 2003;134: 57-61. 
[19] Moghbelinejad S, Alizadeh S, Mohammadi G, Khodabandehloo F, Rashvand Z, Najafipour R, Nassiri-AsI M. The effects of quercetin on the gene expression of the GABA A receptor a5 subunit gene in a mouse model of kainic acid-induced seizure. The Journal of Physiological Sciences 2017;67: 339-343.

[20] Nassiri-AsI M, Hajiali F, Taghiloo M, Abbasi E, Mohseni F, Yousefı F. Comparison between the effects of quercetin on seizure threshold in acute and chronic seizure models. Toxicology and industrial health 2016;32: 936-944.

[21] Abdalla FH, Schmatz R, Cardoso AM, Carvalho FB, Baldissarelli J, de Oliveira JS, Rosa MM, Nunes MAG, Rubin MA, da Cruz IB. Quercetin protects the impairment of memory and anxiogenic-like behavior in rats exposed to cadmium: Possible involvement of the acetylcholinesterase and $\mathrm{Na}+, \mathrm{K}+$-ATPase activities. Physiology \& behavior 2014;135: 152-167.

[22] Nassiri-Asl M, Moghbelinejad S, Abbasi E, Yonesi F, Haghighi M-R, Lotfizadeh M, Bazahang P. Effects of quercetin on oxidative stress and memory retrieval in kindled rats. Epilepsy \& Behavior 2013;28: 151-155.

[23] Nieoczym D, Socała K, Raszewski G, Wlaź P. Effect of quercetin and rutin in some acute seizure models in mice. Progress in Neuro-Psychopharmacology and Biological Psychiatry 2014;54: 50-58.

[24] Cavas M, Beltrán D, Navarro JF. Behavioural effects of dimethyl sulfoxide (DMSO): changes in sleep architecture in rats. Toxicology letters 2005;157: 221-232.

[25] Malfará WR, Souza AMd, Queiroz RHC. Ranitidine treatment inducing methemoglobinemia in male Wistar rats. Revista Brasileira de Ciências Farmacêuticas 2005;41: 247-252.

[26] Arifin WN, Zahiruddin WM. Sample size calculation in animal studies using resource equation approach. The Malaysian journal of medical sciences: MJMS 2017;24: 101.

[27] Grin'kina NM, Li Y, Haber M, Sangobowale M, Nikulina E, Le'Pre C, El Sehamy AM, Dugue R, Ho JS, Bergold PJ. Righting Reflex Predicts Long-Term Histological and Behavioral Outcomes in a Closed Head Model of Traumatic Brain Injury. PloS one 2016;11: e0161053.

[28] Jackson HC, Nutt D. Investigation of the involvement of opioid receptors in the action of anticonvulsants. Psychopharmacology 1993;111: 486-490.

[29] Rehni AK, Singh I, Kumar M. Tramadol-Induced Seizurogenic Effect: A Possible Role of OpioidDependent Y-Aminobutyric Acid Inhibitory Pathway. Basic \& clinical pharmacology \& toxicology 2008;103: 262-266.

[30] Gilbert P, Martin W. Antagonism of the convulsant effects of heroin, d-propoxyphene, meperidine, normeperidine and thebaine by naloxone in mice. Journal of Pharmacology and Experimental Therapeutics 1975;192: 538-541. 
[31] Yang L, Li F, Ge W, Mi C, Wang R, Sun R. Protective effects of naloxone in two-hit seizure model. Epilepsia 2010;51: 344-353.

[32] Wermeling DP. Review of naloxone safety for opioid overdose: practical considerations for new technology and expanded public access. Therapeutic advances in drug safety 2015;6: 20-31.

[33] Raffa RB, Stone DJ. Unexceptional seizure potential of tramadol or its enantiomers or metabolites in mice. Journal of pharmacology and experimental therapeutics 2008;325: 500-506.

[34] Nakhaee S, Amirabadizadeh A, Brent J, Miri-Moghaddam E, Foadoddini M, Farrokhfall K, Hosseini $\mathrm{M}$, Abdollahi M, Mehrpour $\mathrm{O}$. Tramadol and the occurrence of seizures: a systematic review and metaanalysis. Critical reviews in toxicology 2019;49: 710-723.

[35] Jovanović-Čupić V, Martinović Ž, Nešić N. Seizures associated with intoxication and abuse of tramadol. Clinical toxicology 2006;44: 143-146.

[36] Clarot F, Proust B, Vaz E, Goullé J. Tramadol-benzodiazepines and buprenorphinebenzodiazepines: two potentially fatal cocktails? Journal of clinical forensic medicine 2003;10: 125-126.

[37] Nassiri-Asl M, Naserpour Farivar T, Abbasi E, Sadeghnia HR, Sheikhi M, Lotfizadeh M, Bazahang P. Effects of rutin on oxidative stress in mice with kainic acid-induced seizure. Journal of integrative medicine 2013;11: 337-342.

[38] Dajas F, Juan Andres A-C, Florencia A, Carolina E, Felicia R-M. Neuroprotective actions of flavones and flavonols: mechanisms and relationship to flavonoid structural features. Central Nervous System Agents in Medicinal Chemistry (Formerly Current Medicinal Chemistry-Central Nervous System Agents) 2013;13: 30-35.

[39] Lee B-H, Lee J-H, Yoon I-S, Lee J-H, Choi S-H, Pyo MK, Jeong SM, Choi W-S, Shin T-J, Lee S-M. Human glycine a 1 receptor inhibition by quercetin is abolished or inversed by a267 mutations in transmembrane domain 2. Brain research 2007;1161: 1-10.

[40] Lee B-H, Jung S-M, ngo Lee J-H, Kim J-H, Yoon I-S, Lee J-H, Choi S-H, Lee S-M, Chang C-G, Kim H-C. Quercetin Inhibits the 5-Hydroxytryptamine Type 3 Receptormediated Ion Current by Interacting with PreTransmembrane Domain I. Molecules \& Cells (Springer Science \& Business Media BV) 2005;20.

[41] Alexander SP. Flavonoids as antagonists at A1 adenosine receptors. Phytotherapy Research: An international journal devoted to pharmacological and toxicological evaluation of natural product derivatives 2006;20: 1009-1012.

[42] Marquardt KA, Alsop JA, Albertson TE. Tramadol exposures reported to statewide poison control system. Annals of Pharmacotherapy 2005;39: 1039-1044. 
[44] Hassanian-Moghaddam H, Farajidana H, Sarjami S, Owliaey H. Tramadol-induced apnea. The American journal of emergency medicine 2013;31: 26-31.

\section{Figures}

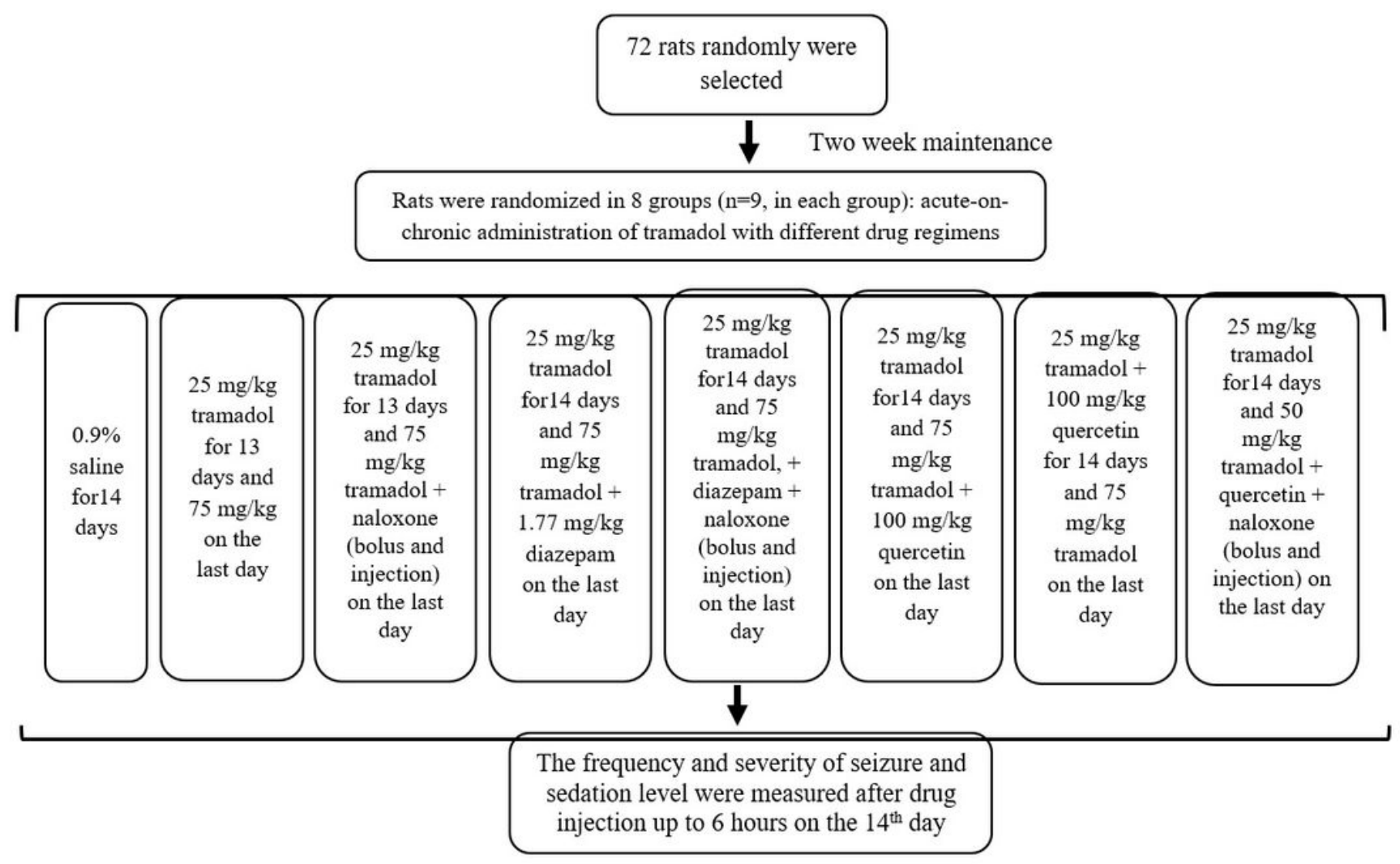

Figure 1

Flow diagram of different experiments and the study process 

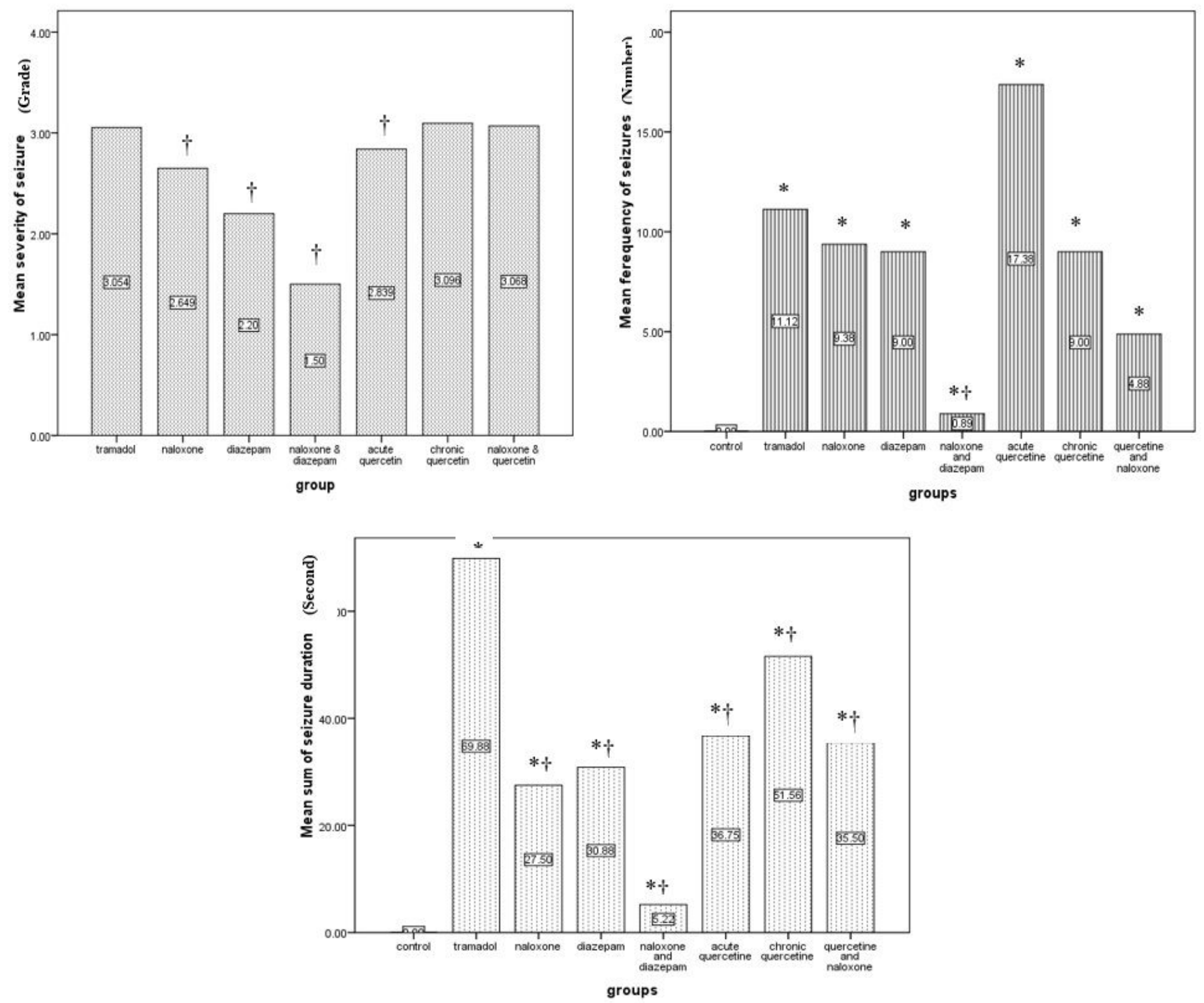

Figure 2

Comparison of the number, severity and duration of seizures in the study groups ${ }^{*} p<0.05$ compared to the Control group; $\mathrm{tp}<0.05$ compared to the Tramadol group 


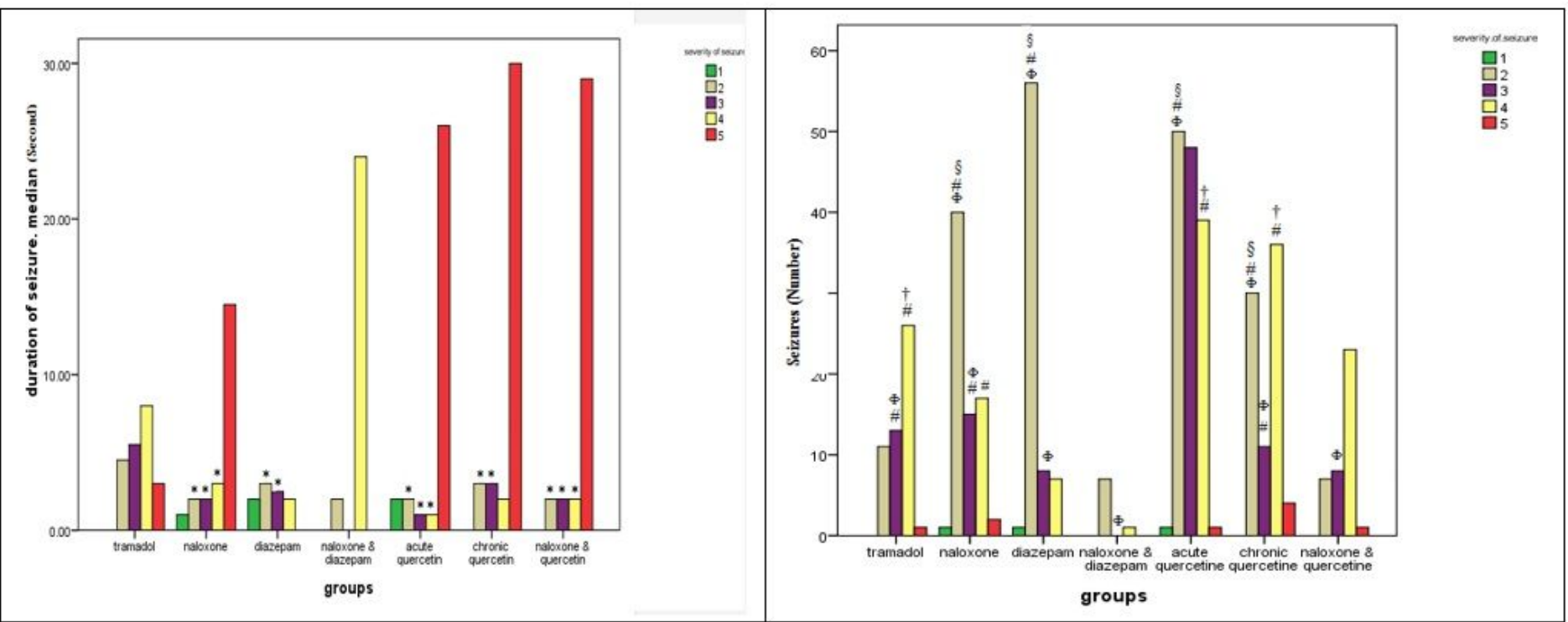

Figure 3

Comparison of the number and duration of seizures according to different severities in the study groups $+\mathrm{p}<0.05$ compared to the Diazepam group; $\# \mathrm{p}<0.05$ compared to the Naloxone-Diazepam group; $\S \mathrm{p}<0.05$ compared to the Naloxone-Quercetin group; $p<0.05$ compared with the Acute Quercetin group; ${ }^{*}<0.05$ compared with the Tramadol group 


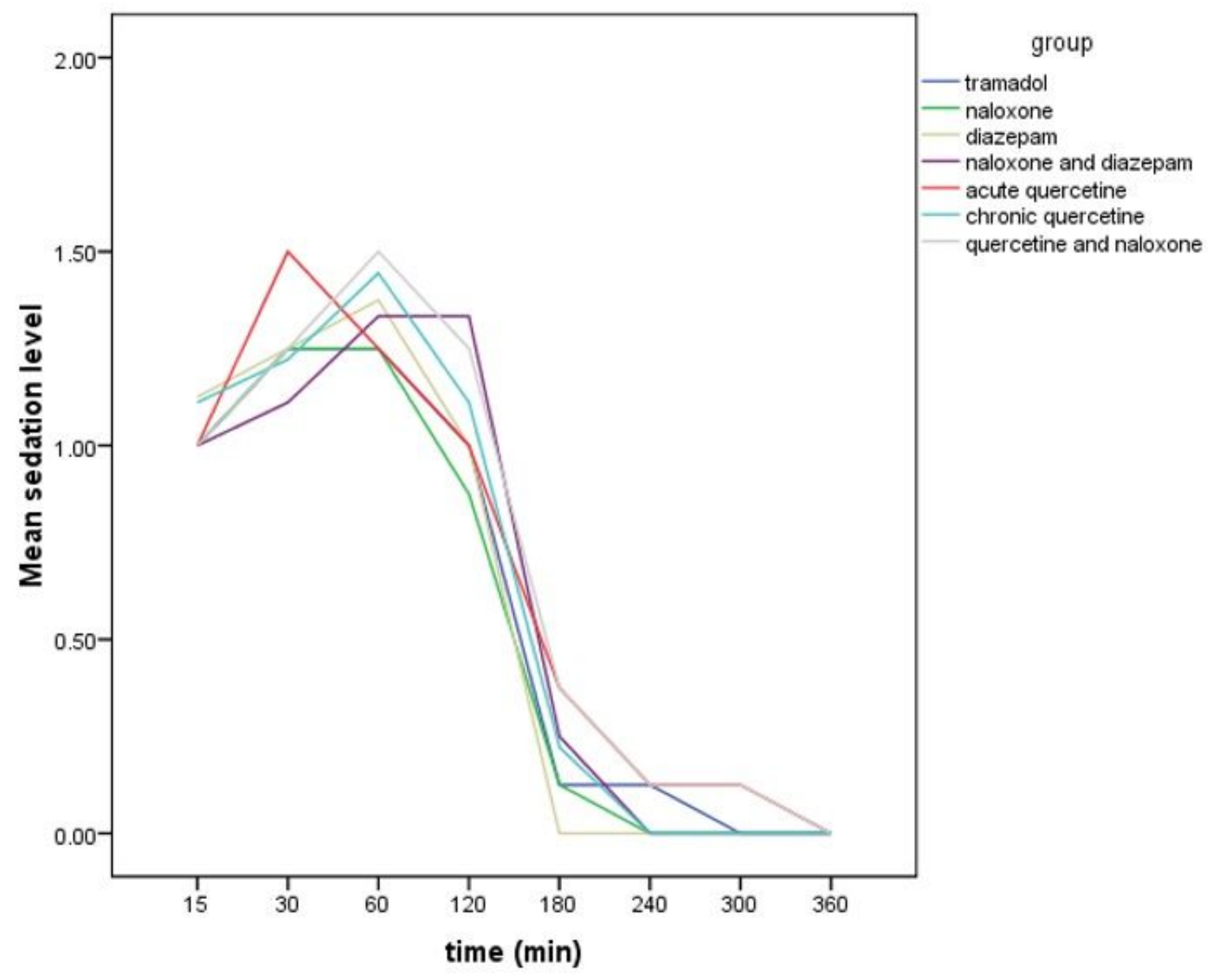

Figure 4

Time-course of average sedation levels in the different treatment groups 